Dr. Beale, as is well known, still holds to the opinion that the nerve-force is electricity, and that the nerves have not only the power of conducting electricity but of evolving it as a vital act on stimulation from the little masses of protoplasm, bioplasm, or living matter with which the nerve-cords are studded. Although there are many objections to this theory, still the badly-conducting power of the nerves for electricity does not appear an insuperable one when we think of the nerve-force merely as a stinulus, for the quantity of a stimulus necessary to rouse up vital action bears an infinitesimally small proportion to the result. But when the same force is assumed to be the efficient cause of muscular contraction, the question assumes a very different aspect. In Dr. Beale's theory the muscular fibre proper is held not to contain protoplasm, and to be incapable of living action or of evolving force, the contraction belng produced by inductive electric action on the sarcous particles, which causes them to change their position and thus approximate the ends of the muscular fibre. The source of the electricity is said to be the protoplasm masses contained in the muscles, in continuous contact with the motor nerves, and it is conveyed to the muscular fibres by loops of fine nerve-fibres crossing them in various directions. In this theory, even supposing insulation to be complete, it is obvious that the conducting power of the nerve-fibre becomes of supreme importance, because not the stimulus only, but the whole force of muscullar motion, must be conveyed by it. Now, the nerve-cords do conduct alectricity certainly, but so many million times worse than metallic wires, that the loss of energy by transformation into heat must be enormous. Such a loss is inconsistent with the cconomy of nature and with the actual facts; therefore, unless the nerve-force is a specific force different from surface-electricity, galvanism, and magnetism, though analogous to them, and probably easily convertible into electricity, Dr. Beale's theory caunot be upheld. I have not yet seen any reply by Dr. Beale to this objection.

JOHN DRYSDALE

Liverpool

\section{Kirkes' Physiology}

IN a letter headed "Kirkes' Physiology," in NATURE of last week, signed "W. Percy Ashe," your correspondent would not appear to be practically acquainted with the semi-lunar valves at the base of the great vessels emerging from the beart, for his argiments, although perfectly correct in themselves, and based on well-known physical laws, do not, I submit, apply in the instance he quotes, for the simple reason that the conditions necessary for their application do not exist.

Let us consider brienty the shape of the sinuses of Valsalva during the diastole of the ventricles of the heart. For our purpose we shall be sufficiently correct in describing them as three inverted, cropty, and slightly truncated pyramids ; one surface, the outer one, of each, is formed by the arterial soat, whilst the ot er two surfaces, constituting the semi-lunar valve, are in apposition with the corresponding surfaces of the other two valves. Now, the pressure over the whole surface of the sinus may be divided into four pressures, one sustained by each of the three sides, and one by the bottom.

The three sides sustain an equal pressure, but the two inner ones constituting the valve are by far the weakest, and the pressure on each of these is really supported by an equal pressure on the corresponding surfaces of the other two valves, and consequently may be considered as $n i l$; whilst the pressure on the third side is resisted by its own strength, and it is formed, as I have said, by the wall of the artery, which is particularly strong at this point.

The remaining pressure is sustained by the bottom or truncated apex of the pyramidal pouch. This pressure is greater in proportion to its extent of surface than the other pressuresthe column of fluid being higher-and this surface directly rests on and is partially embedded in the structure of the ventricle, which must thus undoubtedly support it.

Therefore the idea that "the reflux is most efficiently sustained by the muscular substance of the ventricle," which is the main part of Mr. Savory's theory, is most directly confirmed by the actual construction of the valves, and which your correspondent may see for himself by making a vertical section through the aortic values in a sheep's heart.

As at the time of the greatest pressure on the valves the ventricles are dilating, it follows that they cannot reduce the area of the valves at that time, as your correspondent in his last remarks would seem to imagine, nor in fact can they ever do so. 4. Granville Place, Blackheath E. PRIDEAUX

\section{The Rhinoceros in New Guinea}

Liteut. SIDNey SMith, late of M.M.S. Basizisk, reports that while engaged in surveying on the north coast of Papua, between Huon Bay and Cape Basilisk, being on shore with a party cutting frewood, ihe observed in the forest the "droppings" (excrement) of a rhinoceros in more than one place, the bushes in the neighbourhood being also broken and trampled as if by a large animal. The presence of so large an animal belonging to the Asiatic fauna in Papua is an important fact.

Skins of a very fine species of Bird of Paradise, having plumes of a brilliant red in place of the yellow plumes of the commm species $(P . a p o d a)$, were obtained from the natives further to the eastward.

Chester, Jan. 2r ALFRED O. WALKER

[We should be inclined to doubt very seriously the occurrence of any rhinoceros in New Guinea. At any rate, the important fact, as our correspondent terms it, cannot be considered as established.

The red-plumed Paradise Bird of the south of New Guinea has been named by Mr. Sclater, Paradised riggiana (P. Z. S., I873, p. 559), from skins sent home by Mr. D'Albertis.-Ev.]

\section{Thomson's "Malacca"}

IN your review (NATURE, vol. xi. p. 207) of Mr. J. Thons son's very interesting work on the "Straits of Malacca, IndoChina, and China," you have justly acknowledged that the author " nakes no pretension to have travelled in the interests of science, but only to be a photographer and an observer of the ways of men;" and as his excellent book will no doubt have a wide circulation, it may perhaps not be an unthankful office to correct two statements with reference to the natural history of Penang, which I had some opportunity of studying during a sojoum there of some eighteen months.

Our author, describing the noise made by the insects on Penang Hill, says: "One beetle in particular, known to the natives as the 'trumpeter' busies himself all day long in producing a booming noise with his wings." Had Mr. Thomson succeeded in observing one of these insects whilst "booming," which he states he was unable to do, I think he would have found the musician to have been no beetle at all, but one of the Cicadidx, and the sound not produced by the wings, but, as is generally known, internally, by the vibration of a membrane set into action by a special muscle. These insects are abundant at Penang, one species, Dundabia imperatoria, being particularly large, and which, with several other species, were taken by myself when there. It is nothing unusual for these insects to be wrongly described by natives, as we are told by Mr. Gervase F. Mathew, R.N. (in the Entomologist's Monthly Magazine), that in Tobago Cicalla gigas makes a noise like the whistle of a loco. motive; and he was told by the natives that the scund was that of the "tree-Iocust." At Surinam it is said Cicada tibicen is called the "harper," on account of its giving forth a sound like that of a harp.

Mr. Thomson also tells us (p. 35), when describing planter life in Province Wellesley, that the planters, when driving home at night from one estate to another, have the possibility of an encounter with an orang-outan, a rhinoceros, or a tiger. The orang, however, is not found there at all, and I know of no instance of an attack by a rhinoceros. In fact, that animal is so scarce that during my whole stay there the only report of one which I heard was that the animal's dung had been seen in the jungle. Tigers are still anything but scarce, but during my many nightly rides whilst living on the sugar plantations I am happy to say I never heard or saw one, nor was our roll-call ever diminished by that animal. The tiger there is a midnight prowler, but confines limself more to pigs, goats, and dogs The wild animals are gradually being beaten back by the cultivation of the land, and the same may be said of even the insects. No doubt they abound in the centre of the peninsula, and there also, no doubt, may be found the Negrito stock, of which our author has given us a good photograph as found at Johore.

The illustrations of this very interesting book are excellent, and photography seems to be doing for anthropology what spectrum analysis is still achieving for astronomy.

Streatham Cottage, West Dulwich W. L. DISTANT

\section{Bees and Flowers}

My children noticed with much interest, last autumn, the curious manner that the bees attacked the flowers of the Antir. 
Hizum majus, making a hole at the bottom of the corolla of the flower near the stalk, and so getting at the honey from the outside. It was too late in the season to be able to observe it much, or often, but we are pleased to find others have seen it too.

In Sir John Lubbock's lecture at the London Institution he said some "humble-bees sucked the honey of the French bean and scarlet-runner in the legitimate manner, while other bees cut a hole in the tube, and so reached it surreptitiously."

T'his flower I speak of is one with the corolla much more marked than those the lecturer quoted. Next season we will hope to watch it again, and see if it only happens late in the year, for the injured blossoms seemed to wither very soon after the incision was made.

Tunbridge, Jan. 9

\section{Iron Pyrites. -Curious Phenomenon}

SoM k iron pyrites exhibited in a particular case in the Maid. slone Museum have crumbled into a coarse, finely-divided mass. The specimens have been exhibited for about two months, and the decomposition has been efiected in that time. Some other specimens recently removed from another case are becoming soft.

Could any of your readers account for this, and has such a thing ever been observed before? F'REIERIC CASE

Maidstone, Jan. I9

\section{OUR ASTRONOMICAL COLUATN}

ANIARES AS A DOUBLE STAR.-The small bluish companion of Antares was detected by Mitchel at the Observatory of Cincinnati in July 1845 . Measures taken. by him in the summer of $1 \$ 46$ are published in No. 4 of his Sillerel Mcsscnger. They gave the distance $2 " .52$, the companion preceding on the parallel, at the epoch 184659 , and Mitchel thought this distance was half a second greater than at the time he discovered the small star. He mentions that on the 13 th of August, 1846 , he saw the star distinctly at 5.30 P.M., "the sun shining, unobstructed by clouds or mist." Early in the year 1848 , Antares was repeatedly measured by Bond with the great refractor of Harvard College, and by Dawes in this country. Their mean result, weighted according to the number of nights, is-

1848.24: Position ... $273^{\circ} \%$ r. Distance ... $3^{\prime \prime} 574$.

The proper motion of the large star, thuligh small, is still sufficiently sensible. Leverrier (Annales, tome ii.) assions for the secular motion, - os.059 in Right Ascension, and $-3^{\prime \prime} \cdot 36$ in Declination. If the above angle and distance are brought up to the present time with these values, we find on the assumption of merely optical proximity of the companion-

I $\$ 75^{\circ} 25$ : Position ... 2880.8. Distance ... 3 " 54 .

We would suggest that the star should be carefully re-measured, now that it is drawing away from the sun's place in the morning sky, to decide on the optical or physical connection of the components. Dawes' last measures in I 864 certainly rather favour the latter view, but they were made on a single night, and the object is one of difficult observation. It will be seen that on the assumption of optical duplicity, the distance is just now very nearly stationary, but the change of angle during the last twenty-five years amounts to I 5 degrees, and will be easily confirmed or otherwise.

THE "TEMPORARY STARS" OF TYCHO BRAHE AND KEPSER. - The position of the famous star of 1572 in the constellation Cassiopea, with which Tycho's name is usually associated, has been determined with all the precision that his observations admit of, by Prof. Argelander, of Bonn. His place, reducing to the commencement of the present year, is in

$$
\begin{aligned}
& \text { Right Ascension } \quad \ldots \quad \ldots \text { oh. } 17 \mathrm{~m} \text {. } 525^{\circ} 6 \\
& \text { North Declination } \ldots . \quad \ldots .63^{\circ} 27^{\prime} \quad 8^{\prime \prime} \text {. }
\end{aligned}
$$

Ncar to this position is a star of about the eleventh magnitude, which, by micrometrical comparison with two of its neighbours meridionally fixed, is found to have for the same epoch,

Right Ascension

It is, therefore, distant less than one minute of arc from the most reliable position of Tycho's star that can now be assigned. On this account alone it would be worthy of attention, but we are able to state, further, that during the last four years this small star has exhibited slight fluctuations of brightness at irregular intervals, which increases the probability of its identity with the star of 1572 . It may also be noted that in August 1874 there was a decided ruddiness in its light.

Kepler's observations of the star which suddenly assumed such extraordinary brilliancy in the constellation Ophiuchus in the autumn of $\mathrm{I} 604$, are contained in his work "De Stellâ novâ in pede Serpentarij," but the best position we possess is doubtless that deduced by Prof. Schönfeld of Manheim, from the observations of David Fabricius. For the commencement of the present year we have

Right Ascension $\quad \ldots \quad \ldots \quad$ I $\quad \ldots$ h. 23m. 89."9

South Declination ... ... $2 l^{\circ} 22^{\prime} \quad I 6^{\prime \prime}$.

This position is probably liable to greater error than in the case of 'Tycho's star.

The nearest object at the present time is a star of the twelfth magnitude (or rather fainter), following the above place $6 \mathrm{~s}^{\circ} 5$ and $2 \frac{1}{2}^{\prime}$ south of it, which has not sensibly varied during the last few years, but it is a suspicious circumstance that Chacornac has entered upon his chart No. 52, a tenth magnitude about 8s. preceding Schönfeld's place, and nearly on the parallel of declination, which is not now visible, or was not last summer. The neighbourhood reguires to be closely watched. The observer may set the circles of his equatoreal for Oeltzen 16872, R.A. I 7 h. $23 \mathrm{~m} .34 \mathrm{~s}$., N.P.D. I $1 \mathrm{~L}^{\circ} 23^{\prime}$. The observations for Chacornac's chart were made between the 3 ist of May and 1 ath of August, 186r.

THE ZODIACAL Lighi, - On the evening of Sunday last, the 24th inst., a surprisingly bright display of this as yet problematical phenomenon was exhibited. There was a repetition on the following evening, but in a less favcurable sky. The light had the usual yellowish or pale iemon tinge of the more notable exhibitions in these latitudes. The axis of the light appeared to pass $\lambda$ $P$ iscium, and the vaguely-defined apex was situate somewhere about ig Arietis, but it was not possible to locate it with anything like precision. The light was broad and of a deeper, perhaps, ruddy tint near the horizon. The display to which we have adverted, excelled in brightness any that has been witnessed in the neighbourhood of London for many years. It appears very probable that opportunities for favourable application of the spectroscope may be afforded in the dark evenings of the present and following months.

\section{PLANETARY THEORIES *}

THE theory of Neptunc, which I have the honour of presenting to-day to the Academy, completes the ensemble of the fundamental theories of the planetary system, of which the first dates back to September 16 , 1839 , thirty-five years ago.

The numerous developments added year after year are all mentioncd in the organ of the Academy. Some of them figure only by their titles, and as they are scattered through a great number of volumes, the Academy will no doubt permit me, at the moment when I have arrived at

* "New Theory of the Motion of the Planet Neptune; with Remarks on the crscmble of the Theories of the eight principal Pancts, Mercury, Venus, the Eat th. Mars, Jupiter, Saturn, Urarus, and Neptune" A paper resd liefore the French Academy of Sciences by M. Leverricr, December 21,1874 . 